\title{
HISTÓRIA DE INSTITUIÇÕES ESCOLARES E MICRO HISTÓRIA
}

\author{
José Luís Sanfelice ${ }^{1}$ \\ FE/UNICAMP - HISTEDBR \\ sanfelice00@hotmail.com
}

\begin{abstract}
RESUMO
O presente artigo foi produzido para tentar responder a uma pergunta freqüente dos alunos que se encontram em diferentes níveis de formação. Em síntese, indagam: estudar a história de instituições escolares, ou de uma delas, é optar pela metodologia da microhistória? Revisitei o trabalho de Vainfas (2002), um "historiador de ofício", para construir a resposta mais didática que me foi possível. Concluo, com ele, que a definição que opõe a micro-história a uma história da totalidade não se dá pelo recorte do tema objeto da pesquisa, mas sim em decorrência da perspectiva de análise. Ressalto a relevância de se focar com prioridade o debate sobre os diferentes referenciais teórico-metodológicos.
\end{abstract}

Palavras-chave: história de instituições escolares; micro-história; história da totalidade; referenciais teóricos.

\section{HISTORY OF SCHOOL INSTITUTIONS AND MICROHISTORY}

\begin{abstract}
This paper was written in an attempt to answer a question frequently asked by students in different levels of education. In short, they ask: is the study of educational institutions, or of one of them, an option for the microhistory methodology? I have revisited the work of VAINFAS (2002), a "professional historian", to produce the most didactic answer possible. I conclude with him that the definition that places microhistory against a total history is not given by the theme object of the research, but as a result of the analysis perspective. The relevance of focusing mainly on the debate about the different theoreticalmethodological references is emphasized.
\end{abstract}

Keywords: history of school institutions; microhistory; total history; theoretical references.

Provocado pela indagação freqüente se a ampliação da produção de trabalhos sobre a história de instituições escolares significa uma opção pela micro-história, proponho-me tentar responder a questão de forma a mais didática possível. A origem da pergunta em geral deseja estabelecer um contraste ou um antagonismo entre a micro-história e uma história da totalidade e, não raro, insinua que os procedimentos metodológicos de cada uma delas são bem distintos.

Do ponto de vista teórico-metodológico os embates travados entre as perspectivas que dão ênfase ao particular (local), versus aquelas que enfatizam o geral (nacional ou uma certa totalidade) não são recentes. O mesmo se poderia dizer de abordagens de prismas 
exclusivistas em detrimento de outras mais abrangentes do real. Os seguidores das opções metodológicas dialéticas, por exemplo, enfrentam cotidianamente os desafios de se estabelecer uma adequada e racional explicação para as partes de um objeto estudado, a sua totalidade, e esta em relação ao real que a circunda de forma próxima ou distante (Sanfelice, 2005, pp. 69-94).

Do ponto de vista da historicidade dos embates, é necessário que se estabeleça uma interlocução mais próxima com os historiadores chamados 'de ofício'. Acredito que VAINFAS $(2002$, p.11) possa nos ajudar, pois ele pretendeu esclarecer "o que é a microhistória, suas propostas, seus métodos, o lugar que ocupa na chamada Nova História" . Considera que os debates em torno da micro-história, no Brasil, datam da década de 1980, quando aqui foram traduzidos livros "de história das mentalidades dos franceses e dos livros da chamada nova história cultural dos italianos, ingleses e norte-americanos" (p. 8). A micro-história foi, nas suas palavras, mal recebida: “...expressão do pior tipo de história que se poderia fazer... emblema mais negativo da chamada Nova História" (p. 8). Adversários? Os defensores da história marxista, da história social totalizante. Admite, entretanto, que havia grande confusão entre as concepções da história das mentalidades, da história cultural, da Nova História, micro-história e que a nova geração de historiadores não contribuiu para dirimir as dúvidas. As novas correntes historiográficas chegavam ao Brasil com o atraso de dez ou quinze anos e ao mesmo tempo. A história de tipo sócioeconômica, preferencialmente marxista, presente nos cursos de história e na pesquisa histórica funcionou como uma barreira ao que se passava na historiografia ocidental.

Independente das opiniões de VAINFAS (2002) sobre os historiadores marxistas e o seu papel na historiografia brasileira, cabe, sem polemizar, o registro de dois aspectos: os embates não foram suprimidos e se manifestam com maior ou menor ênfase dependendo do locus em que ocorrem. De acordo com o lado pelo qual se opta, o marxismo já morreu ou, então, ele é atualíssimo. Claro está que também existem posições intermediárias.

Quanto ao segundo aspecto, ele diz respeito a um possível paralelo entre as constatações de VAINFAS (2002) no campo geral da história e historiografia brasileira e a História da Educação. Não farei tal paralelo para não perder o fio condutor do tema proposto, mas não tenho muitas dúvidas que vários trabalhos produzidos na rubrica História da Educação demonstram com competência que ela, embora relativamente mais recente na prática acadêmica brasileira, repercuti sobejamente os principais meandros da historiografia nacional ou ocidental. Limito-me, no presente caso, a arrolar nas Notas, ao final, algumas obras indicadoras da presente observação ${ }^{(2)}$.

O historiador VAINFAS registra que a bibliografia teórica, do início dos anos 80, veio a se beneficiar com a obra "Os métodos da história"(3), pois ela auxiliou no aclaramento da história econômica, social, demográfica e marxista, mas não tratou da história cultural e da micro-história. Os debates se arrefeceram na segunda metade dos anos 80, mas continuaram confusos até que fosse publicado 'Domínios da história' ${ }^{(4)}$. O novo livro, na sua opinião, tornou mais nítidas as fronteiras entre história das mentalidades e nova história cultural, mas a micro-história continuou padecendo de equívocos. Por conta da constatação, surge o empenho de VAINFAS em esclarecer o que é a micro-história, como já dito.

Primeiro: a micro-história não é sinônimo de história das mentalidades que, por sua vez, seria herdeira direta dos analistas, uma menção ao movimento dos Annales, surgido na França a partir de 1929. Algumas tendências teriam se afastado das origens, mas M. Bloch e Febvre lideraram um movimento que combateu a história historicizante 'événementiélle' - dos séculos XIX e início do XX. O alvo foi a história preocupada com 
fatos singulares, de natureza política, diplomática e militar feita mediante a análise de documentos verdadeiros e autênticos. Combateram também a história que se furtava ao diálogo com as demais Ciências Humanas e propuseram uma história problematizadora do social com "ênfase no estudo das condições de vida material, embora sem qualquer reconhecimento da determinância do econômico na totalidade social, à diferença da concepção marxista da história" (p. 17, grifo meu). Desejavam uma história interdisciplinar, uma síntese interdisciplinar, a Revolução Francesa da historiografia.

Para VAINFAS (2002), Bloch e Febvre inauguravam o estudo das mentalidades, "delas fazendo um legítimo objeto de investigação histórica, embora condicionassem o seu estudo a uma perspectiva globalizante e sintética de história social" (p. 18).

Após os anos 60, os historiadores franceses teriam retomado as antigas preocupações dos fundadores dos Annales quanto ao estudo do mental. A historiografia francesa passou a trilhar os rumos das mentalidades "concebidas como estruturas de crenças e comportamentos que mudam muito lentamente, tendendo por vezes à inércia e à estagnação" (p. 20). O campo tornou-se privilegiado pelos historiadores da "terceira geração' dos Annales, sob a batuta de J. Le Goff, J. Revel e A. Burguiere viabilizando que a historiografia francesa caminhasse do "porão ao sótão", "metáfora então usada para exprimir a mudança de preocupações da base socioeconômica ou da vida material para os processos mentais, a vida cotidiana e suas representações" (p. 22). A absorção de LeviStrauss e de Foucault, pela historiografia, impulsionou a importância que se passou a dar aos discursos e rituais, à sexualidade, às prisões, aos micropoderes e às doenças, por exemplo. E ainda pesou em favor das mentalidades as rebeliões dos anos 60 e o desencantamento da esquerda ocidental com o modelo soviético de socialismo.

O mesmo autor considera precipitada a caracterização dessa historiografia francesa pelos seus temas: assuntos ligados ao cotidiano e às representações: "o amor, a morte, a família, a criança, as bruxas, os loucos, a mulher, os homossexuais, o corpo, a morte, os modos de vestir, de chorar, de comer ou de beijar" (p. 23). O mesmo acontece com relação ao seu estilo de apego à narrativa e à descrição em detrimento da explicação globalizante. Vainfas, entretanto, reconhece as dificuldades que surgiram na definição conceitual da história das mentalidades quanto ao seu campo teórico e metodológico:

Daí a indicação freqüente da história das mentalidades simplesmente como a que se dedica às religiosidades, às sexualidades, aos comportamentos, aos temas escondidos no "sótão" das sociedades e metáforas assemelhadas. Em segundo lugar, não é rara a delimitação das mentalidades por oposição quer à história econômica, quer à história das idéias (p. 24).

A seguir, VAINFAS extrai do artigo de LeGoff, "As mentalidades - uma história ambígua"(5), três idéias básicas que sintetizo:

a) - as mentalidades são tão abrangentes que diluem as diferenças da estratificação social da sociedade.

b) - o que há de comum em todos os homens de uma sociedade, mentalidades, situa-se de preferência no campo do 'irracional e do 
extravagante', daí decorrendo a noção de inconsciente coletivo a ser estudado por uma pesquisa 'arqueopsicológica'

c) - o tempo das mentalidades, é o tempo braudeliano da longa duração, ou seja que muda mais lentamente.

No mesmo artigo Le Goff critica os marxistas que não conseguiram passar de maneira convincente das infra-estruturas para as superestruturas, vendo nas mentalidades uma correção da deficiência teórica do marxismo ou mesmo para substituí-lo, embora acabe por reconhecer que é "um erro grosseiro" desligar as mentalidades "das estruturas e da dinâmica social", admitindo a existência de "mentalidades de classes ao lado de mentalidades comuns" (p. 26).

Em A história do quotidiano ${ }^{(6)}$, Le Goff traz as mentalidades travestidas de cotidiano e revê alguns dos seus conceitos anteriores, mas "Nada, porém, sequer próximo à teoria marxista da história ..." (p. 27).

Michel Vovelle, historiador marxista ${ }^{(7)}$, rejeitou a noção de inconsciente coletivo, a autonomia do mental e recusou-se a ver as mentalidades como o essencial da história. Propôs uma articulação entre o conceito de mentalidade e o de ideologia, entendida essa última em termos de dominação de classe.

No debate, três dilemas:

a) - reconhecer a relativa autonomia das mentalidades e a necessidade de articulá-las a totalidades históricas explicativas;

b) - a perspectiva da longa duração e o risco de fossilizar a história, tornando imperceptíveis as mudanças;

c) - resgatar o lado humano e até individual da história (sentimentos, desejos, fobias) e o dever de explicar seu sentido coletivo e global.

Dilema maior: o impasse entre a crise do racionalismo e a própria tradição racionalista do mundo ocidental. A crise do racionalismo foi a brecha por onde as mentalidades invadiram o território dos historiadores, retirando-lhes a motivação explicativa e empobrecendo o compromisso social inerente ao ofício de historiador. A "máquina de guerra" do ceticismo duvida da diferença entre história e ficção, sugerindo que ambas não passam de gêneros de narrativa literária.

$\mathrm{Na}$ prática, a história das mentalidades da historiografia francesa privilegiou os temas religiosidades, sexualidades e suas representações, sentimentos coletivos (o medo, p. ex.) e a vida cotidiana em regiões ou cidades. E se expandiu mundo afora com adaptações, tornando possível um balanço crítico indicativo de três variantes: 
a) - uma história das mentalidades herdeira da tradição dos Annales, que reconhece que o estudo do mental só faz sentido se articulado a totalidades explicativas;

b) - uma história das mentalidades assumidamente marxista, preocupada em relacionar os conceitos de mentalidade e ideologia que valoriza a ruptura e a dialética entre o tempo longo e o acontecimento revolucionário (Vovelle) e

c) - uma história das mentalidades pouco problematizadora dos objetos e por isso a mais citada pelos adversários, caracterizada pela simples e ingênua 'reconstituição' de épocas ou episódios ou direcionada aos 'temas picantes', sensacionalistas (beijar, chorar, onanismo, cardápios) (p. 31-32).

Com uma incursão pela produção da historiografia das mentalidades, VAINFAS estabelece um critério de uma melhor historiografia e de uma historiografia periférica diferenciando-as pela relevância dos temas, pela perícia da pesquisa documental, erudição, originalidade, densidade teórica e inteligência das interpretações.

No primeiro grupo, "a descrição exaustiva se combina com interpretações de fôlego e à busca do sentido histórico de ações e discursos, jamais renunciando aos sujeitos sociais em confronto" (pp. 48-49).

Um dos problemas dos que vêem nada mais que 'migalhas' nesses estudos é o parti pris doutrinário e dogmático que só admite como totalidade legítima de serem estudados temas ligados à história socioeconômica ou perspectivas que adotem a priori o determinismo econômico como único eixo aceitável da explicação histórica.

(...) esse é um tipo de avaliação muito marcada pela tradição braudeliana e especialmente pelo marxismo à moda de Althusser. Dela resulta uma avaliação totalmente míope do que pode constituir uma totalidade histórica ou uma perspectiva de síntese no recorte do objeto de investigação. Pois, independente do tema - e toda pesquisa histórica tende a recortar monograficamente o objeto de investigação - o que importa é a perspectiva de análise (p. 49).

Prevalece então, na boa historiografia das mentalidades, sempre segundo VAINFAS, a perspectiva da história total, problematizada, não meramente descritiva, preocupada com hierarquias e contrastes sociais - incluindo, sem dogmatismo, a luta de classes; uma história preocupada com aplicações bastante gerais e globais.

Conclui: "uma das características fundamentais da micro-história que muito a diferencia da história das mentalidades: sua renúncia, aí sim, à história geral, à contextualização sistemática, à explicação, à totalidade e à síntese. Renúncia que, como veremos a seu tempo, longe está de exprimir uma igual renúncia à teoria" (p. 51). 
Da história das mentalidades à história cultural

Vainfas sugere que as resistências às mentalidades e certas radicalizações na defesa delas, comprometedoras da própria disciplina, acabaram por fazer que certos historiadores das mentalidades se refugiassem, com seus temas e objetos na chamada história cultural ou nova história cultural, mais consistente em suas principais versões e que tem como primeira característica a rejeição do conceito de mentalidade substituído por história da cultura. A seguir, nova história cultural, para se distinguir da disciplina acadêmica dedicada a estudar as manifestações "oficiais" ou "formais" da cultura de determinada sociedade: as artes, a literatura e a filosofia. Revela especial apreço pelas manifestações das massas anônimas: as festas, as resistências, as crenças heterodoxas. Afeição, sobretudo, pelo popular. Preocupação em resgatar mais explicitamente o papel das classes sociais. E, uma história plural, com caminhos alternativos para a investigação histórica. Carlo Ginzburg, Roger Chaartier e Edward Thompson seriam três exemplos distintos.

\section{Gênese da micro-história}

Anos 80, abrigando temas da história das mentalidades. Fruto do debate historiográfico dos anos 70, 80, da crise do paradigma marxista, e de outros modelos de história totalizante, bem como da frágil solução tentada pela história das mentalidades. Os seus propósitos faziam parte das críticas à história das mentalidades, ao relativismo, ao irracionalismo e à redução do trabalho do historiador a uma atividade puramente retórica. Em muitos aspectos alinhou-se à nova história cultural.

A micro-história surgiu na Itália e, talvez, a obra chave seja $O$ queijo e os vermes de Carlo Ginzburg. Ecletismo temático, temporal e espacial marcaram suas origens. A microhistória é o estudo monográfico sobre um tema particular. Um cruzamento da história cultural com a história social. Um gênero diferente de fazer e contar história que renuncia à história total, à história síntese dos Annales e, acrescento, por suposto, ao marxismo. Privilegia a narrativa descritiva e busca expor a história para os que a conhecem e também para os que não a conhecem, por meio da narrativa descritiva dos casos miúdos. Não renuncia a busca da veracidade dos fatos. Usa fontes em profusão e não transforma a verdadeira história em ficção, mas especula muito, passando ao leitor as dúvidas do historiador. "Apega-se obsessivamente às mínimas evidências que a documentação pode fornecer para dar vida a personagens esquecidos e desvelar enredos e sociedades ocultadas pela história geral" (p. 103). A micro-história, de certo modo, se vincula à nova história cultural, mas com ela não se confunde. É um campo específico distinto da história das mentalidades.

o historiador seria, assim, por excelência, um pesquisador de evidências periféricas, aparentemente banais, incertas, porém capazes, se reunidas em uma trama lógica, de reconstruir a estrutura e dinâmica de seus objetos (p. 109). 
Um historiador detetive ou um médico auscultador e uma história como 'ciência do particular', do caso irrepetível e único. É indutiva, especulativa e não pode evitar certa dose de subjetivismo. A pesquisa de indícios é o seu método de prática historiográfica que reconhece o particular como objeto da história. É micro temática e micro analítica. Sintetizo:

Microtemas: estudos exaustivos de comunidades periféricas ou de personagens sem nenhuma celebridade na História, com $\mathrm{H}$ maiúsculo, e não a temas gerais que estavam no 'sótão' da história e foram resgatadas pelas 'mentalidades' - tal como a história do medo, do purgatório ou da morte no Ocidente (p. 111).

Microanálise: descrição e interpretação de casos minúsculos e periféricos à luz de uma história geral, e não à história que, embora debruçada sobre o mental, busca inserir seus objetos em totalidades explicativas (p. 111).

Metodologia: pesquisa detalhada, microscópica. Sobressai a redução da escala de observação como ponto de partida metodológico, o que a diferencia, explicita e assumidamente da história síntese (p. 115).

Agora, sintetizo afirmações decorrentes:

- a micro-história não se ocupa em definir a fundo e a priori, quer na pesquisa, quer na exposição dos casos, o caráter da sociedade na qual se insere o enredo, a comunidade ou o personagem estudado (p. 116).

- na micro-história prevalece, no tocante à delimitação do campo social estudado, procedimentos de nominação dos atores e da caracterização de perfis individuais no interior de determinado grupo ou classe, mais do que a definição geral de classe ou de grupo ao qual pertence (p. 117).

- importa analisar não apenas os fatos ocorridos, mas os dilemas, os impasses, as incertezas de cada um - ou mais comumente, dos personagens centrais (p. 117).

- a micro-história recusa os usos mais convencionais da noção de contexto. Sugere uma idéia de contexto que se limita ás múltiplas experiências, contraditórias e ambíguas, por meio das quais os homens constroem o mundo e suas ações! Quer iluminar aspectos da história geral que forçosamente escapam a um olhar macro-histórico das sociedades (p. 119).

- a multiplicidade de papéis desempenhados pelos protagonistas da narrativa microhistórica, inseridos em múltiplos contextos não-compartimentados, implica, assim, a recusa em hierarquizá-los (a classe social ou o estado civil do indivíduo podem ter a mesma importância).

- a micro-história diz respeito ao sujeito - o historiador que reduz sua escala analítica - e simultaneamente ao objeto, no caso os enredos e conflitos protagonizados por agentes anônimos da realidade histórica. 
- a narrativa micro-histórica evita explicações generalizantes, de modo que o historiador assume, quando muito, o papel de narrador onisciente de uma trama. A narrativa é temperada com as dúvidas do próprio historiador.

- por meio da narrativa amiudada de certo caso, o que se pretende é exibir a relação entre determinado sistema de regras ou determinações históricas da sociedade estudada e as ações individuais (p. 199).

- o tempo da micro-história é o tempo das estruturas e o tempo do acontecimento.

- os temas preferidos são ligados a comunidades específicas, às situações limites e às biografias. Busca o local, a aldeia, o bairro, o círculo de vizinhança, até mesmo a casa, de preferência a região ou mesmo o município. Rarissimamente o 'nacional' funciona como referência geográfica ou política no enquadramento de tema micro-históricos, e muito menos os espaços supranacionais, quer teóricos (o capitalismo, o absolutismo) quer geográficos (o Mediterrâneo, o Atlântico).

Concluindo: A micro-história se direciona, portanto, quer nos estudos de comunidades, de situações limites ou de personagens populares, para aquilo que está na sombra da história. À sombra do panteão das histórias nacionais ou oficiais. À sombra das mitologias, ideologias e religiões.

\section{Considerações}

Que lições tirar da obra de VAINFAS (2002) agora revisitada? Penso que muitas, em especial pesquisadores iniciantes da História da Educação que nem sempre conseguem perceber o movimento, também histórico, da historiografia. Quanto à perspectiva crítica do autor em relação aos historiadores marxistas, já disse acima que não vou polemizar no presente texto.

Vou centrar-me no propósito anunciado: a escolha por uma história de instituições escolares significa uma opção pela micro-história? Respondo de forma enfática, apropriando-me das palavras de VAINFAS (2002, p. 39): “... independente do tema - e toda pesquisa histórica tende a recortar monograficamente o objeto de investigação - o que importa é a perspectiva de análise".

Se considero que na História da Educação o tema-objeto central é a educação, a história de instituições escolares constitui-se em um dos seus possíveis recortes monográficos. Nada ainda se define, entretanto, quanto à perspectiva de análise.

É preciso observar que dois movimentos podem ocorrer: a) o pesquisador escolhe o tema monográfico sem ter uma prévia opção clara quanto à perspectiva de análise, por razões as mais variadas ou, b) o pesquisador escolhe o tema monográfico exatamente em decorrência da sua perspectiva de análise. No primeiro caso, não necessariamente, mas com freqüencia, os trabalhos podem se tornar inexpressivos. No segundo caso o "foco" ou "o olhar" poderão estar condicionados pela opção teórica pela qual já se decidiu. Há aqui, pelo menos em tese, maiores chances de trabalhos de melhor qualidade, embora devam, com certeza, chegar a resultados muito distintos e dependendo da competência teóricometodológica do pesquisador. VAINFAS (2002) exauriu-se em demonstrar como no 
movimento da historiografia os campos de interesse foram se alterando. O mesmo é possível se constatar que vem ocorrendo na história da Educação.

Posso então afirmar que a escolha por uma história das instituições escolares não leva mecanicamente à micro-história, pois a perspectiva da análise é que se torna decisiva (Sanfelice, 2009) e, na prática, os pesquisadores da história da educação estão se valendo das diferentes opções disponíveis. Penso que o debate de fundo deva se travar no campo teórico desses referenciais que, acredito, está secundarizado. Entendo também que, por conseqüência, a formação dos pesquisadores da área, desde a iniciação científica ao doutorado, sofre comprometedoras restrições.

Finalmente, é certo que há antagonismos entre a micro-história e uma história da totalidade, tanto quanto os procedimentos metodológicos de cada uma são distintos. VAINFAS (2002) foi feliz na exposição que busquei sintetizar e não é necessário repetir as características da micro-história apontadas por ele. Como não é a proposta teóricometodológica que venho modestamente sugerindo para a história das instituições escolares, resta o desafio de expor, em outra ocasião, alguns constitutivos, repito, teóricometodológicos, para uma história das instituições escolares numa perspectiva da história da totalidade.

\section{$\underline{\text { Referências }}$}

SANFELICE, J. L. História e historiografia de instituições escolares. In: Revista HISTEDBR on-line. Campinas, $n^{\circ}$ 35, p. 192-200, set. 2009. www.histedbr.fae.unicamp.br

SANFELICE, J. L. Dialética e pesquisa em educação. In: LOMBARDI, J. C. \& SAVIANI, D. (orgs.). Marxismo e educação: debates contemporâneos. Campinas: Autores Associados, 2005, p. 69-94.

VAINFAS, R. Micro-história. Os protagonistas anônimos da história. Rio de Janeiro: Campus, 2002.

$\underline{\text { Notas }}$

1. Professor titular de História da Educação da Faculdade de Educação da UNICAMP. Pesquisador permanente do Grupo de Estudos e Pesquisas "História, Sociedade e Educação no Brasil" - HISTEDBR.

2. MONARCHA, C. (org.). História da Educação Brasileira. Formação do campo. Ijuí: Ed. UNIJUI, 2005. GONDRA, J. G. (org.). Pesquisa em História da Educação no Brasil. Rio de Janeiro: DP\&A, 2005. LOMBARDI, J. C. \& SAVIANI, D. (orgs.). Navegando pela História da Educação brasileira. 20 anos de HISTEDBR. Campinas, SP: Autores Associados: HISTEDBR, 2009. BITTAR, M. \& FERREIRA JR., A. História, epistemologia marxista e pesquisa educacional brasileira. In: Educação e Sociedade. Campinas: Cedes, vol. 30, m./ag. - 2009, p. 489-511.

3. CARDOSO, C. F. \& BRIGNOLI, H. P. (orgs.). Os métodos da História. Rio de Janeiro: Ed. Graal, 1983. 
4. CARDOSO, C. F. \& VAINFAS, R. (orgs.). Domínios da História. Ensaios de teoria e metodologia. Rio de Janeiro: Campus, 1997.

5. LE GOFF, J. As mentalidades - uma história ambígua. In: LE GOFF, J. \& NORA, P. (orgs.). História: novos objetos. Rio de Janeiro: Francisco Alves, 1976, p. 68-83.

6. LE GOFF, J. A história do quoditiano. In: ARIES, P. et allii. História e nova história. Lisboa, Teorema, 1989, p. $73-82$.

7. VOVELLE, M. Ideologias e mentalidades: um esclarecimento necessário. In: VOVELLE, M. Ideologias e mentalidades. São Paulo: Brasiliense, 1987, p. 9-25.

Artigo recebido em: 03/11/10

Aprovado em: 30/11/10 